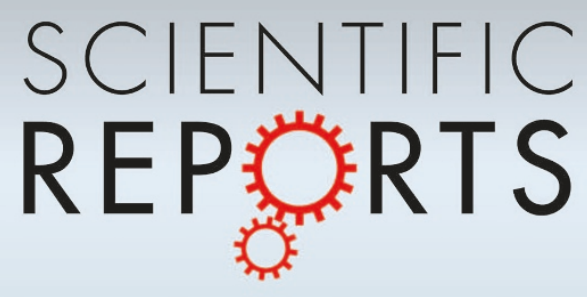

OPEN

SUBJECT AREAS:

MATERIALS CHEMISTRY

NANOWIRES

SYNTHESIS AND PROCESSING

Received

22 July 2013

Accepted

28 January 2014

Published

12 February 2014

Correspondence and requests for materials should be addressed to S.H.Y. (shyu@ustc.edu.

$\mathrm{cn})$

\section{Carbon nanofiber aerogels for emergent cleanup of oil spillage and chemical leakage under harsh conditions}

\author{
Zhen-Yu Wu, Chao Li, Hai-Wei Liang, Yu-Ning Zhang, Xin Wang, Jia-Fu Chen \& Shu-Hong Yu
}

Division of Nanomaterials \& Chemistry, Hefei National Laboratory for Physical Sciences at Microscale, Collaborative Innovation Center of Suzhou Nano Science and Technology, Department of Chemistry, University of Science and Technology of China, Hefei 230026, P. R. China.

To address oil spillage and chemical leakage accidents, the development of efficient sorbent materials is of global importance for environment and water source protection. Here we report on a new type of carbon nanofiber (CNF) aerogels as efficient sorbents for oil uptake with high sorption capacity and excellent recyclability. Importantly, the oil uptake ability of the CNF aerogels can be maintained over a wide temperature range, from liquid nitrogen temperature up to ca. $400^{\circ} \mathrm{C}$, making them suitable for oil cleanup under harsh conditions. The outstanding sorption performance of CNF aerogels is associated with their unique physical properties, such as low density, high porosity, excellent mechanical stability, high hydrophobicity and superoleophilicity.

W ith the rapidly increasing use and transport of oils and chemical solvents, oil spillage and chemical leakage accidents occur frequently worldwide. Such accidents can cause severe pollution of coastal waters (e.g., the Gulf of Mexico oil spill accident in 2010) and our living environment, and they can also lead to a significant loss of valuable resources ${ }^{1-4}$. Current strategies used to tackle these problems can be categorized into three main types: chemical methods (i.e., dispersion, in situ burning, and the use of solidifiers), physical methods (i.e., sorbents, skimmers, and booms), and biological methods (i.e., bioremediation ${ }^{5-10}$. Among these, sorbents are considered as one of the most promising approaches. In particular, they facilitate the sorption process given their large sorption capacity, high uptake rate, and potential recyclability ${ }^{11-14}$.

Traditional oil sorption materials mainly comprise inorganic mineral products, natural materials, synthetic polymers and polymer-based composites ${ }^{6}$. Inorganic mineral products (such as zeolites ${ }^{15}$, expanded perlite ${ }^{16}$, and sepiolite ${ }^{15}$ ) have been used for removal of various organic pollutants for a long time. However, the limited mineral reserves and inconvenience of recycling hamper the industrial, large-scale applications of these materials. Natural materials (such as carbonized fir fibers ${ }^{5}$, wool $^{17}$, pith bagasse ${ }^{18}$, and vegetable fibers ${ }^{19}$ ) can overcome these disadvantages. Nevertheless, these natural materials exhibit low sorption capacity and poor selectivity for the uptake of spilled oils. The sorption capacities of synthetic polymers and polymer-based composites (such as polyester $^{20}$, polyurethane ${ }^{21,22}$, butylrubber ${ }^{23}$, and polydimethylsiloxane-coated material $\mathrm{s}^{24-26}$ ) are significantly higher than those of the two former groups, but the polymers degrade very slowly compared with mineral products or natural materials, and their environmental and ecological impact remains unclear. Hence, it is crucial to develop affordable, environmentally benign oil sorbents with high sorption capacity and selectivity, as well as good recyclability, and which work under harsh conditions such as extreme temperatures.

Over the past years, carbon-based aerogels have attracted interest in various fields (e.g., energy storage and conversion devices, sensors, stretchable conductors, and catalyst supports) due to their unique physical properties, such as low apparent density, high electrical conductivity, porosity, and specific surface area ${ }^{27-34}$. As sorbent materials, various carbon-based aerogels, such as carbon nanotube (CNT) sponge ${ }^{8,35}$, spongy graphene $e^{36,37}$, graphene/CNT hybrid foam, ${ }^{11,38}$ and carbon nanofiber aerogel ${ }^{39}$, exhibit very high sorption capacities, good recyclability and environmental friendliness. Nevertheless, expensive equipments and complex technologies involved in their manufacture hamper the large-scale production of these carbon-based aerogels for practical applications. Recently, our group has developed a template-directed hydrothermal carbonization (HTC) process to produce carbonaceous nanofiber hydrogels/aerogels on a macroscopic scale $(12 \mathrm{~L})$ by using glucose as the precursor ${ }^{25,40}$. The as-obtained carbonaceous nanofiber aerogels were coated with polydimethylsiloxane (PDMS) and shown to 


\section{a}
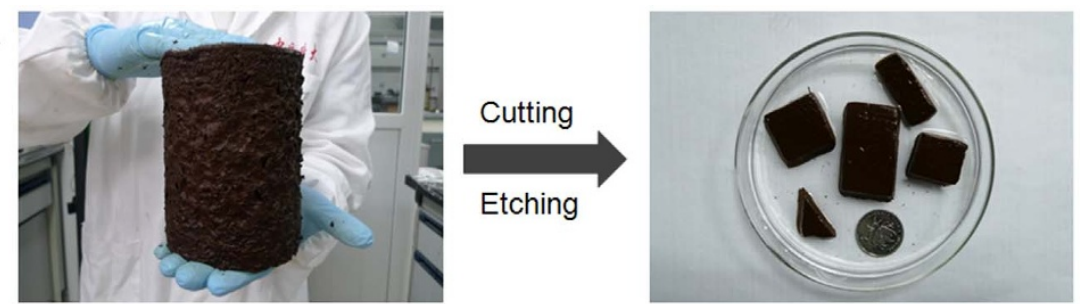

Freeze

drying
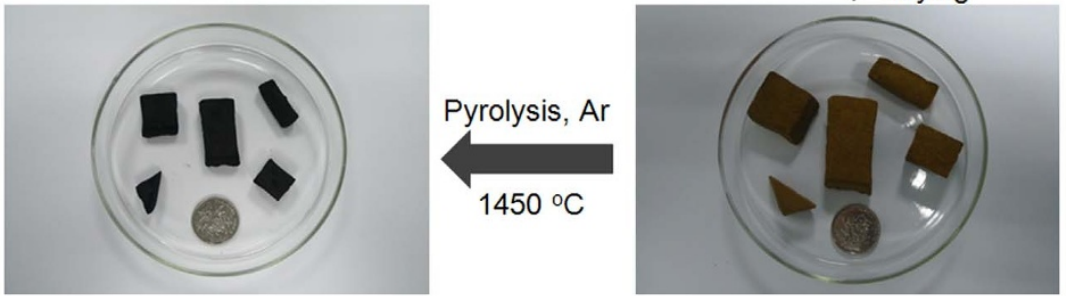

b

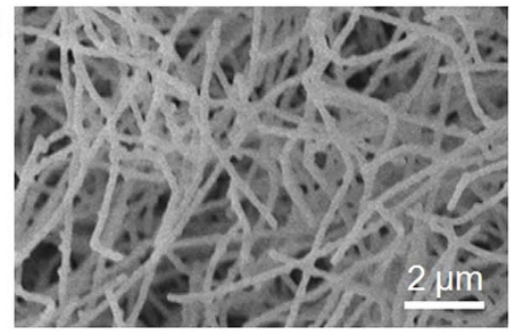

C

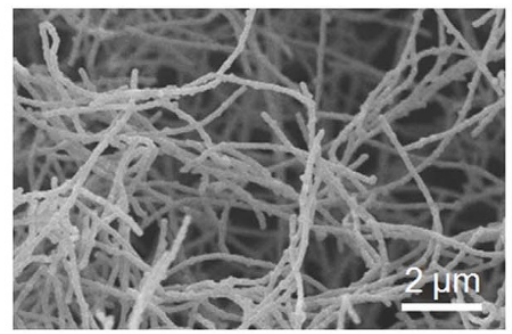

Figure $1 \mid$ The synthetic pathway of CNF aerogels and their morphologies. (a) The fabrication process of CNF aerogels. (b, c) SEM images of the carbonaceous nanofiber and CNF aerogels, respectively.

be effective for selective uptake of oils. However, the fabrication processes have potential environmental risk for using the polymer PDMS.

Herein, we report on a simple route to fabricate carbon nanofiber (CNF) aerogels on a large scale from macroscopic-scale synthesized carbonaceous nanofiber hydrogels. The resulting CNF aerogels have a self-assembled, interconnected, three-dimensional (3D) network structure with a very low apparent density of $c a .10 \mathrm{mg} \mathrm{cm}^{-3}$ and a high porosity of $>99 \%$. In addition, they possess excellent mechanical stability, high hydrophobicity and superoleophilicity. When used as sorbents, the CNF aerogels absorb a variety of oils and organic solvents showing high sorption capacities approaching 139 times their own weights and good recyclability. Notably, pollutants can be absorbed over a wide range of temperatures.

\section{Results}

Synthesis of CNF aerogels. Fig. 1a describes the synthetic pathway. Briefly, a volume of $1200 \mathrm{~mL}$ carbonaceous nanofiber monolithic hydrogel synthesized by the HTC method was first cut into pieces of desired shapes and sizes with a sharp blade. After washing and chemical etching to remove Te nanowires, the purified carbonaceous nanofiber hydrogels were formed ${ }^{25}$. To prevent the hydrogel networks from collapsing, a freeze drying technique was used for water removal to form dried porous aerogels. The resulting materials were then pyrolyzed at $1450^{\circ} \mathrm{C}$ for $2 \mathrm{~h}$ under an argon atmosphere to generate black CNF aerogels.

Scanning electron microscopy (SEM) images reveal that the freeze-dried aerogel consists of carbonaceous nanofibers selfassembled into a porous, interconnected, 3D framework (Fig. 1b). High-magnification SEM and transmission electron microscopy (TEM) observations indicate that these nanofibers with a diameter of $c a .140 \mathrm{~nm}$ are highly interconnected with large numbers of junctions (see Supplementary Information, Fig. S1 and Fig. S2). The $3 \mathrm{D}$ network of the nanofibrous aerogel can survive well even after pyrolysis at a high temperature. However, the volume of obtained $\mathrm{CNF}$ aerogel shrank to $c a .50 \%$ of that of the original carbonaceous nanofiber aerogel, while the fiber diameter decreased to $c a .125 \mathrm{~nm}$ (Fig. 1c), owing to evaporation of some volatile species during the pyrolysis process. No obvious difference in morphology was observed from the top surface or side-walls of the CNF aerogels. The macroscopic sizes of the as-synthesized CNF aerogels are simply dependent on the sizes of the hydrogels cut in the fabrication procedure (see Supplementary Information, Fig. S3).

Physical properties of the CNF aerogels. The as-prepared CNF aerogel has a very low apparent density of $c a .10 \mathrm{mg} \mathrm{cm}^{-3}$, which is comparable to those of spongy graphene $\left(12 \pm 5 \mathrm{mg} \mathrm{cm}^{-3}\right)^{36}$ and un-densified vertically aligned CNT arrays $\left(10 \mathrm{mg} \mathrm{cm}^{-3}\right)^{41}$, and is much less than those of the traditional carbon aerogels $(100-800 \mathrm{mg}$ $\left.\mathrm{cm}^{-3}\right)^{42,43}$ and hydrophobic nanocellulose aerogels $(20-30 \mathrm{mg}$ $\left.\mathrm{cm}^{-3}\right)^{7}$. A piece of CNF aerogel with a volume of $5.3 \mathrm{~cm}^{3}$ can stand stably on top of a dandelion without deforming it (Fig. 2a). The CNF aerogel porosity is estimated to be $>99 \%$ based on calculations using the apparent density of $c a .10 \mathrm{mg} \mathrm{cm}^{-3}$ for CNF aerogel and a density of $1.95-2.17 \mathrm{~g} \mathrm{~cm}^{-3}$ for $\mathrm{CNF}^{44}$. The high porosity is in accordance with SEM and TEM observations. Despite its low-density property and high porosity, the CNF aerogel exhibits excellent mechanical strength. It can support a weight of at least $500 \mathrm{~g}$ even though the aerogel itself weighs only $56.1 \mathrm{mg}$ (Fig. $2 \mathrm{~b}$ and Fig. S4). The exact mechanical properties of the material were additionally tested by a universal testing machine. The compressive strain-stress curve of the $\mathrm{CNF}$ aerogel reveals that the maximum compressive stress is up to $85 \mathrm{KPa}$ before fracture, which is a high value among the reported low density carbon-based aerogels ${ }^{27}$ (Fig. 2c). We attribute this robust mechanical property of the CNF aerogel to its unique interconnected 3D network structure.

Nitrogen adsorption isotherm analysis reveals a BrunauerEmmett-Teller (BET) surface area of up to $547 \mathrm{~m}^{2} \mathrm{~g}^{-1}$ for the 


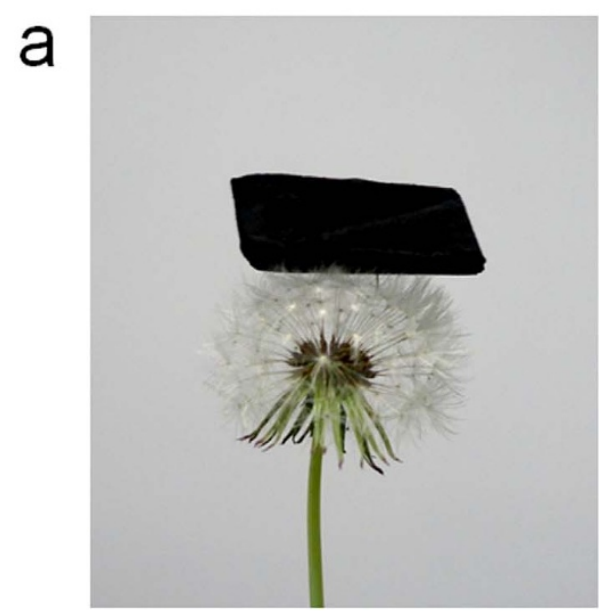

C

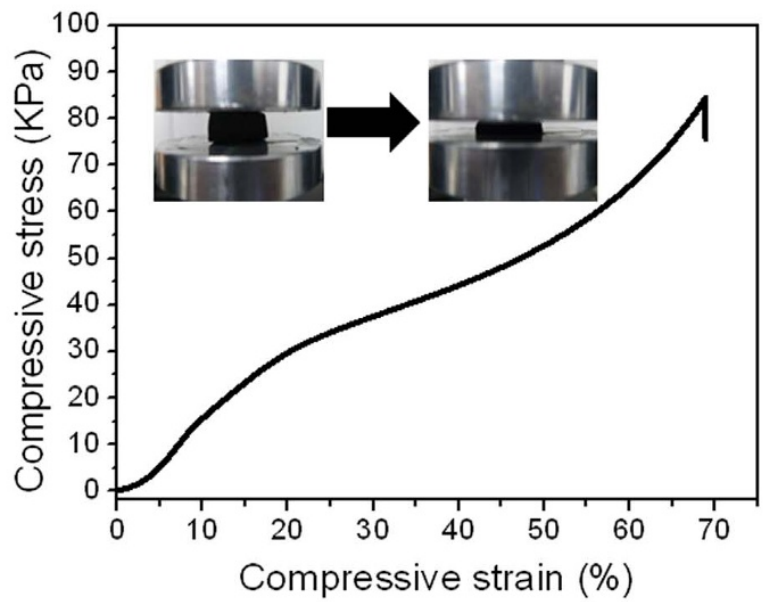

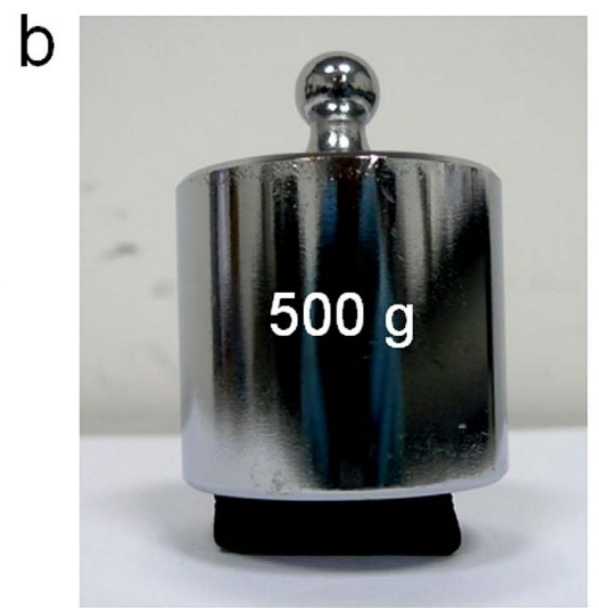

d
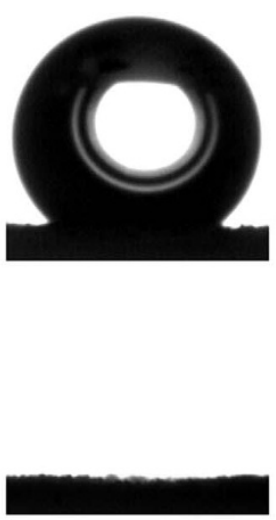

Figure $2 \mid$ Physical properties of CNF aerogels. Photographs of an as-prepared CNF aerogel (mass $=56.1 \mathrm{mg})$ with a size of $3.1 \times 1.7 \times 1 \mathrm{~cm}^{3}$ (a) standing on a dandelion and (b) supporting $500 \mathrm{~g}$ ( $c a .9000$ times its weight). (c) The compressive strain-stress curve of a CNF aerogel; the inset shows the photographs of the CNF aerogel before and after the compressive test. (d) The measurement of contact angle with water (top) and soybean oil (bottom) for CNF aerogel.

CNF aerogel, which is much higher than that of $\mathrm{N}$-doped graphene framework $\left(280 \mathrm{~m}^{2} \mathrm{~g}^{-1}\right)^{33}$ and monolithic graphene aerogels $\left(249 \mathrm{~m}^{2} \mathrm{~g}^{-1}\right)^{45}$ (see Supplementary Information, Fig. S5). The nitrogen isotherm is of type I, a characteristic of microporous materials. The micropores are formed during the pyrolysis process as a result of the evaporation of volatile species. Additionally, the fibers are intertwined together as evidenced by the SEM micrographs, thus forming macropores whose sizes cannot be determined reliably by nitrogen sorption. In other words, the aerogels contain both micropores and macropores. The high porosity of $\mathrm{CNF}$ aerogel is very beneficial for oil-cleanup. A water contact angle (CA) measurement was performed to investigate the surface wettability of the CNF aerogel; it exhibited surface hydrophobicity with a water CA of $135.8^{\circ}$ (Fig. 2d). In contrast to hydrophobic wettability to water, the CNF aerogel showed excellent oleophilic property. When a soybean oil droplet dripped on the surface of the CNF aerogel, it was absorbed immediately and a CA of oil of $c a .0^{\circ}$ was observed (Fig. 2d and Fig. S6). Therefore, the CNF aerogel exhibits high hydrophobicity and superoleophilicity, which is crucial for selective uptake of spilled oils.

\section{Discussion}

Due to its low apparent density, excellent mechanical stability, high porosity, and hydrophobicity/superoleophilicity, the CNF aerogel is an ideal candidate for the sorption of oils and other organic pollutants. When a small piece of the CNF aerogel was placed on the surface of oil-water mixtures, the oil layer (dyed with Sudan III) immediately started shrinking and disappeared completely after a few minutes (Fig. 3a). Similarly, when the CNF aerogel was held to approach phenoxin (also dyed with Sudan III) under water, the phenoxin droplets were rapidly absorbed by the aerogel upon contact (see Supplementary Information, Fig. S7). To further demonstrate the sorption ability of CNF aerogel, we investigated its sorption capacities for different commercial petroleum products (e.g., gasoline, diesel oil, pump oil, etc.) and toxic organic solvents (e.g., bromobenzene, THF, $n$-hexane, etc.). The sorption efficiency can be assessed by weight gain, defined as wt $\%=$ (weight after saturated sorption - initial weight)/initial weight. The CNF aerogel showed outstanding sorption ability for these liquids. In general, the sorption capacities range from 51 to 139 times the weight of the CNF aerogel for a variety of oils and organic solvents (Fig. 3b). The organics were mainly stored in the macropores of the CNF aerogels, so the differences of sorption capacities were related to the densities of organic liquids. The sorption capacities are superior to those of activated carbon $\left(<1\right.$ times) ${ }^{46}$, marshmallow-like macroporous gels (6-14 times $)^{1}$, graphene $/ \alpha$-FeOOH aerogel (13-27 times $)^{47}$, micro-porous polymers $(<33 \text { times })^{12}$, and our previously reported PDMS-coated carbonaceous nanofiber aerogel (40-115 times) ${ }^{25}$; they are comparable to those of hybrid foam of graphene/CNT (80-130 times) $)^{11}$ and CNT sponge (80-180 times) $)^{35}$, but lower than those of ultralight graphene framework (200-600 times) ${ }^{33}$ and ultra-flyweight CNT/ graphene hybrid aerogels (215-743 times) ${ }^{38}$. However, the fabrication of our CNF aerogel is much more facile on a large scale than that 

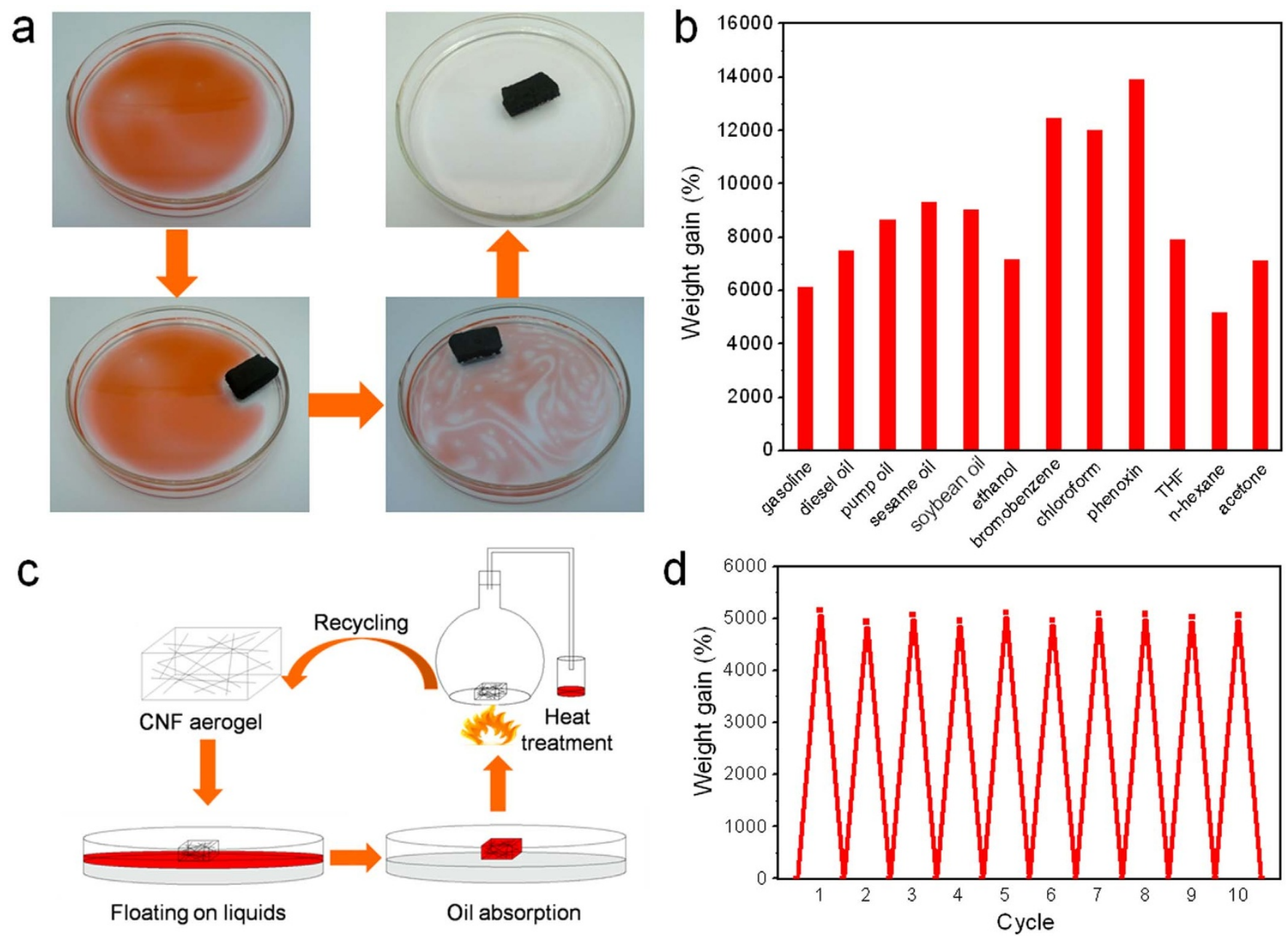

Figure 3 Oil-uptake and recyclability studies of the CNF aerogels. (a) The sequential photographs of CNF aerogel absorbing diesel oil (dyed with Sudan III) on water surface. (b) Sorption capacities of CNF aerogels for various organic liquids in terms of weight gain. (c) Schematic diagram of the CNF aerogel recycling process by heat treatment method. (d) The sorption recyclability of CNF aerogel over ten cycles.

of these graphene-based or CNT-based sorbent counterparts. Based on the sorption capacities of all organic liquids in Figure $3 \mathrm{~b}$ and their densities, we calculated pore volumes of $78-100 \mathrm{~cm}^{3} \mathrm{~g}^{-1}$ for CNF aerogels (see Supplementary Information, Table S1), in good agreement with the value of $c a .99 \mathrm{~cm}^{3} \mathrm{~g}^{-1}$ calculated from the apparent density.

Furthermore, the sorption kinetics of CNF aerogel to four organic liquids were investigated. The sorption capacity $Q_{t}$ of each organic liquid was plotted as a function of the sorption time (see Supplementary Information, Fig. S8). Obviously, the sorption capacities increase with sorption time until saturation. The saturation sorption time of low-viscosity organic solvents (ethanol and phenoxin) is much shorter than that of high-viscosity oils (soybean oil and diesel oil); the saturation sorption time of the two organic solvents is less that $30 \mathrm{~s}$, while it takes more than $900 \mathrm{~s}$ to reach saturation for the two oils. This phenomenon can be understood considering the fact that the low-viscosity organic solvents penetrate the 3D network structure of CNF aerogel much more easily. The sorption kinetics process can be described by the second-order model: ${ }^{8}$

$$
\frac{1}{Q_{m}-Q_{t}}=\frac{1}{Q_{m}}+K t
$$

in which $Q_{t}$ represents the sorption capacity at time $t, Q_{m}$ is the saturated sorption capacity (namely, weight gain), $K$ is the sorption constant, and $t$ is the sorption time. According to Eq. (1), the calculated results match well with the experimental data. All fitting parameters of four kind organic liquids are listed in Table S2. The fitting values of $Q_{m}$ are nearly equal to the weight gains that we measured in Fig. 3b, further indicating an excellent agreement between the sorption kinetics model and experimental data.

Recyclability of the CNF aerogel and recoverability of oils and organic solvents are key requirements in practical oil cleanup applications. We evaluated the recycling potential of CNF aerogel and recovering of oils and organic solvents through a simple sorptiondrying cycle by taking $n$-hexane as an example (Fig. $3 c$ ). The CNF aerogel was first saturated with $n$-hexane and then the material was heated to the boiling point of the absorbate $\left(69^{\circ} \mathrm{C}\right)$, though the evaporation out of $n$-hexane works equally well under ambient conditions. The vapor of the $n$-hexane was collected and condensed for recovery, while the CNF aerogel was regenerated. The process was repeated 10 times to demonstrate recyclability. Over ten repetitions, the CNF aerogel showed stable performance: the aerogel absorbed $c a$. 50 times its dry weight for $n$-hexane, and no obvious decrease of sorption capacity was observed (Fig. $3 \mathrm{~d}$ ); $n$-hexane is released and collected almost entirely during this process. These results suggest that it is easy to reobtain active CNF aerogels and absorbates by a simple sorption-drying cycle. Another recycling method, direct combustion, was shown to be effective as well (see Supplementary Information, Fig. S9).

In addition to sorbents suitable to face oil leakage accidents under ambient conditions, there is a need for materials working effectively 

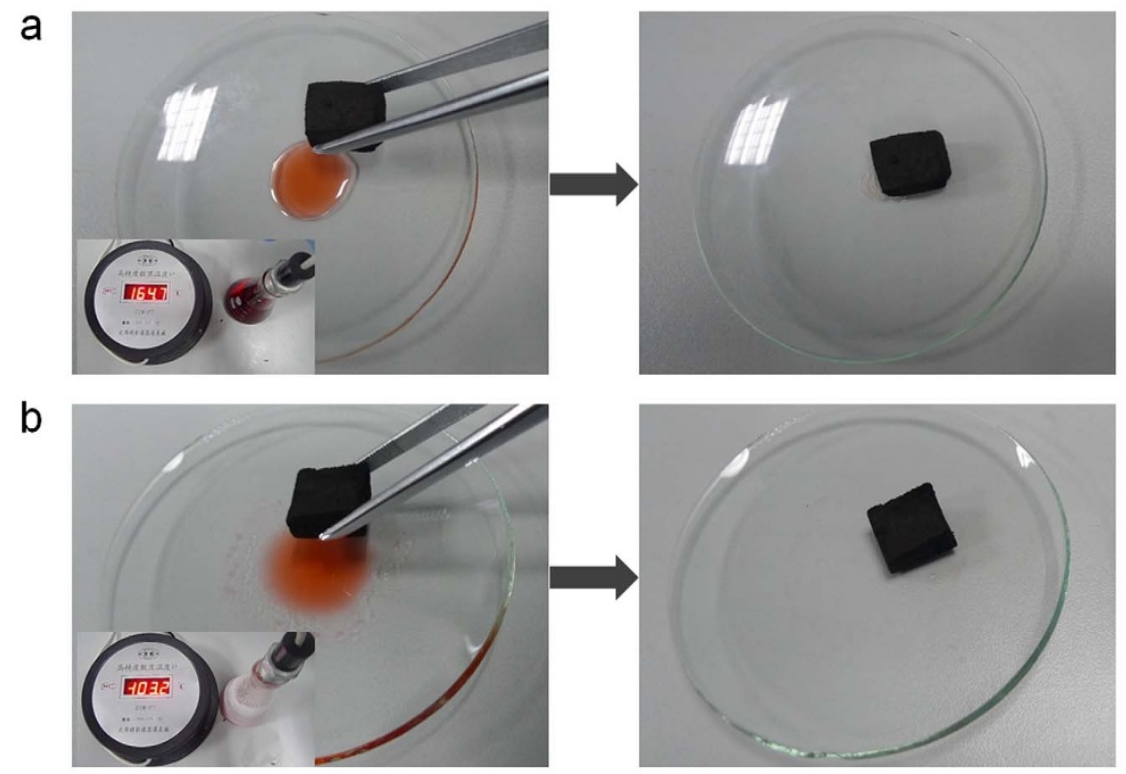

Figure $4 \mid$ Sorption of oils under harsh conditions. The CNF aerogels absorb (a) hot soybean oil $\left(164.7^{\circ} \mathrm{C}\right)$ and $(\mathrm{b})$ cold ethanol $\left(-103.2^{\circ} \mathrm{C}\right)$, indicating their utility under unusual conditions; the inset photographs show temperatures of the absorbates.

under harsh conditions, such as high or low temperatures. Traditional sorbents (such as polyurethane-based and polyethylene-based materials) cannot be used at temperatures above $200^{\circ} \mathrm{C}$, and others will become very brittle at low temperatures. In this regard, our CNF aerogel exhibits exceptional features. When exposed to an ethanol flame, the CNF aerogel did not support any burning and remained inert (see Supplementary Information, Movie S1). After $c a .30$ s of such extreme heating, it was immediately immersed into liquid nitrogen $\left(\mathrm{LN}_{2}\right)$. No decomposition or material change occured; even upon repetition of this treatment for several times, the shape, volume, and inherent $3 \mathrm{D}$ porous structure of $\mathrm{CNF}$ aerogel remained unchanged, demonstrating that the CNF aerogel can withstand extreme temperatures and rapid temperature change. Further, thermogravimetric analysis (TGA) shows that the CNF aerogel has a weight loss of less than $8 \%$ at a temperature of up to $850^{\circ} \mathrm{C}$ in $\mathrm{N}_{2}$ and can tolerate a high temperature of approximately $400^{\circ} \mathrm{C}$ in air (see Supplementary Information, Fig. S10). After the CNF aerogel was heated in an ethanol flame or frozen in $\mathrm{LN}_{2}$ for five minutes, it still exhibited a good mechanical property and supported at least 5000 times its own weight. There was only a slight difference among the original, burned, and freezed samples in the compressive strainstress test (see Supplementary Information, Fig. S11). Meanwhile, the high and low temperature treatments had no obvious influence on the hydrophobic and oleophilic properties of the CNF aerogel.

As the sorption properties are insensitive to temperatures, the CNF aerogel is considered to be an ideal oil sorbent for dealing with accidents. Hot soybean oil $\left(164.7^{\circ} \mathrm{C}\right)$ and cold ethanol $\left(-103.2^{\circ} \mathrm{C}\right)$ are absorbed by the $\mathrm{CNF}$ aerogel equally completely as room temperature (Fig. 4, and also see Supplementary Information, Movies S2 and S3). Limited only by the measuring range of our thermometer, even hotter (e.g., $400^{\circ} \mathrm{C}$ ) and colder (e.g., $\left.-196^{\circ} \mathrm{C}\right)$ organic liquids were also absorbed by our CNF aerogel, demonstrating overall excellent performance over a wide temperature range. These results indicate that the CNF aerogel can be used in some special situations, such as oil spillage in the polar zone and high or low temperature organic solvents leakage accidents, for which conventional sorbent materials are not suitable.

In summary, we have developed a novel and simple method to fabricate macroscopic CNF aerogels composed of interconnected 3D networks of nanofibers on a large scale. The CNF aerogel possesses unique physical features, such as low apparent density, high porosity, excellent mechanical stability, high hydrophobicity and superoleophilicity. As an oil sorbent, the CNF aerogel exhibits high sorption capacity, excellent recyclability and high selectivity. Importantly, the sorption performance of the CNF aerogel can be maintained over a wide temperature range, from liquid nitrogen temperature up to $c a$. $400^{\circ} \mathrm{C}$, which extends its potential applications. Furthermore, the asprepared CNF aerogel is a promising material for other novel applications, e.g., serving as 3D electrode material in energy storage and conversion devices.

\section{Methods}

All chemicals were of analytical grade and used as received without further purification.

Preparation of TeNWs templates ${ }^{48}$. Briefly, $10.0 \mathrm{~g}$ PVP and $0.92 \mathrm{~g} \mathrm{Na}_{2} \mathrm{TeO}_{3}$ were dissolved in $320 \mathrm{~mL}$ of deionized water under vigorous magnetic stirring at room temperature. Then $17 \mathrm{~mL}$ of hydrazine hydrate $(85 \%, \mathrm{w} / \mathrm{w} \%)$ and $33 \mathrm{~mL}$ of aqueous ammonia solution were added into the above solution. The mixture was transferred to a Teflon vessel ( $500 \mathrm{~mL}$ total volume) held in a stainless steel vessel. The steel vessel was placed in an oven and heated at $180^{\circ} \mathrm{C}$ for $3 \mathrm{~h}$.

Preparation of carbonaceous nanofiber hydrogels ${ }^{25}$. In a typical process for fabricating carbonaceous nanofiber hydrogels, $500 \mathrm{~mL}$ of acetone was added into $150 \mathrm{~mL}$ of as-prepared TeNWs solution to precipitate the TeNWs. Then the TeNWs were collected by centrifugation $(8000 \mathrm{rpm})$ and dispersed into $1180 \mathrm{~mL}$ glucose solution (80 g glucose) with vigorous magnetic stirring. Hydrothermal treatment of the above solution at $180^{\circ} \mathrm{C}$ for $18 \mathrm{~h}$ using an autoclave with a total volume of $1600 \mathrm{~mL}$ resulted in $1200 \mathrm{~mL}$ of monolithic gel-like product.

Preparation of CNF aerogels. The wet carbonaceous gel was taken out directly from the Teflon container and cut into pieces of desired shape and size. Small pieces of carbonaceous nanofiber hydrogels were soaked successively in ethanol $(12 \mathrm{~h} \times 5$ times), acidic $\mathrm{H}_{2} \mathrm{O}_{2}$ solution ( $\mathrm{HCl}: \mathrm{H}_{2} \mathrm{O}_{2}: \mathrm{H}_{2} \mathrm{O}=2: 5: 23$, v/v, $12 \mathrm{~h}$ ), and deionized water (12 h $\times 5$ times) at room temperature to remove impurities and TeNWs templates. The purified hydrogel was frozen in liquid nitrogen $\left(-196^{\circ} \mathrm{C}\right)$ and freezedried in a bulk tray dryer (Labconco Corporation, USA) at a sublimating temperature of $-48^{\circ} \mathrm{C}$ and a pressure of $0.04 \mathrm{mbar}$. The obtained carbonaceous nanofiber aerogels were transferred into a tubular furnace for pyrolysis under an argon flow. The carbonaceous nanofiber aerogels were heated to $500^{\circ} \mathrm{C}$ at a heating rate of $2^{\circ} \mathrm{C} / \mathrm{min}$, kept this temperature for $1 \mathrm{~h}$, then heated to $1450^{\circ} \mathrm{C}$ at $5^{\circ} \mathrm{C} / \mathrm{min}$ and held at this temperature for $2 \mathrm{~h}$ to allow for complete pyrolysis. They were then cooled to $500^{\circ} \mathrm{C}$ at $5^{\circ} \mathrm{C} / \mathrm{min}$ and finally cooled to room temperature naturally to yield black $\mathrm{CNF}$ aerogels.

Instruments. Scanning electron microscopy (SEM) images were obtained from a Zesiss Supra 40 scanning electron microscope at an acceleration voltage of $5 \mathrm{kV}$. Transmission electron microscope (TEM) images were obtained from a Hitachi H7650 transmission electron microscope with CCD imaging system on an 
acceleration voltage of $120 \mathrm{kV}$. The wetting properties of different samples were evaluated through contact angle tests, which were performed by the CAST2.0 contact angle analysis system at room temperature (Solon Information Technology Co., Ltd, Shanghai, China). The compressive tests of the CNF aerogels were performed by using an Instron 5565A testing machine, equipped with two flat-surface compression stages. The strain ramp rate was maintained at $1 \mathrm{~mm}$ per min for all of the tests. $\mathrm{N}_{2}$ sorption analysis was operated on an ASAP 2020 accelerated surface area and porosimetry instrument (Micromeritics), equipped with automated surface area, at $77 \mathrm{~K}$ using Barrett-Emmett-Teller (BET) calculations for the surface area. The thermogravimetric analysis (TGA) was determined by a TGA Q5000IR analyzer.

1. Hayase, G., Kanamori, K., Fukuchi, M., Kaji, H. \& Nakanishi, K. Facile Synthesis of Marshmallow-like Macroporous Gels Usable under Harsh Conditions for the Separation of Oil and Water. Angew. Chem. Int. Ed. 52, 1986-1989 (2013).

2. Choi, H. M. \& Cloud, R. M. Natural sorbents in oil spill cleanup. Environ. Sci. Technol. 26, 772-776 (1992)

3. Toyoda, M. \& Inagaki, M. Sorption and Recovery of Heavy Oils by Using Exfoliated Graphite. Spill Sci. Technol. Bull. 8, 467-474 (2003).

4. Dalton, T. \& Jin, D. Extent and frequency of vessel oil spills in US marine protected areas. Mar. Pollut. Bull. 60, 1939-1945 (2010).

5. Inagaki, M., Kawahara, A. \& Konno, H. Sorption and recovery of heavy oils using carbonized fir fibers and recycling. Carbon 40, 105-111 (2002).

6. Bayat, A., Aghamiri, S. F., Moheb, A. \& Vakili-Nezhaad, G. R. Oil Spill Cleanup from Sea Water by Sorbent Materials. Chem. Eng. Technol. 28, 1525-1528 (2005).

7. Korhonen, J. T., Kettunen, M., Ras, R. H. A. \& Ikkala, O. Hydrophobic Nanocellulose Aerogels as Floating, Sustainable, Reusable, and Recyclable Oil Absorbents. Acs Appl. Mater. Interfaces 3, 1813-1816 (2011).

8. Gui, X. et al. Recyclable carbon nanotube sponges for oil absorption. Acta Mater. 59, 4798-4804 (2011).

9. Lin, J. et al. Facile control of intra-fiber porosity and inter-fiber voids in electrospun fibers for selective adsorption. Nanoscale 4, 5316-5320 (2012).

10. Lin, J.et al. Co-axial electrospun polystyrene/polyurethane fibres for oil collection from water surface. Nanoscale 5, 2745-2755 (2013).

11. Dong, X. et al. Superhydrophobic and superoleophilic hybrid foam of graphene and carbon nanotube for selective removal of oils or organic solvents from the surface of water. Chem. Commun. 48, 10660-10662 (2012).

12. Li, A. et al. Superhydrophobic conjugated microporous polymers for separation and adsorption. Energy Environ. Sci. 4, 2062-2065 (2011).

13. Nguyen, D. D., Tai, N.-H., Lee, S.-B. \& Kuo, W.-S. Superhydrophobic and superoleophilic properties of graphene-based sponges fabricated using a facile dip coating method. Energy Environ. Sci. 5, 7908-7912 (2012).

14. Zhu, Q., Pan, Q. \& Liu, F. Facile Removal and Collection of Oils from Water Surfaces through Superhydrophobic and Superoleophilic Sponges. J. Phys. Chem. C 115, 17464-17470 (2011).

15. Rajaković-Ognjanović, V., Aleksić, G. \& Rajaković, L. Governing factors for motor oil removal from water with different sorption materials. J. Hazard. Mater. 154, 558-563 (2008).

16. Toyoda, M. \& Inagaki, M. Heavy oil sorption using exfoliated graphite: New application of exfoliated graphite to protect heavy oil pollution. Carbon 38, 199-210 (2000).

17. Radetić, M. M., Jocić, D. M., Jovancčić, P. M., Petrović, Z. L. \& Thomas, H. F. Recycled Wool-Based Nonwoven Material as an Oil Sorbent. Environ. Sci. Technol. 37, 1008-1012 (2003).

18. Hussein, M., Amer, A. A. \& Sawsan, I. I. Oil spill sorption using carbonized pith bagasse: 1. Preparation and characterization of carbonized pith bagasse. J. Anal. Appl. Pyrolysis 82, 205-211 (2008).

19. Annunciado, T. R., Sydenstricker, T. H. D. \& Amico, S. C. Experimental investigation of various vegetable fibers as sorbent materials for oil spills. Mar. Pollut. Bull. 50, 1340-1346 (2005).

20. Zhang, J. \& Seeger, S. Polyester Materials with Superwetting Silicone Nanofilaments for Oil/Water Separation and Selective Oil Absorption. Adv. Funct. Mater. 21, 4699-4704 (2011).

21. Zhu, Q. et al. Robust superhydrophobic polyurethane sponge as a highly reusable oil-absorption material. J. Mater. Chem. A 1, 5386-5393 (2013).

22. Calcagnile, P. et al. Magnetically Driven Floating Foams for the Removal of Oil Contaminants from Water. ACS Nano 6, 5413-5419 (2012).

23. Ceylan, D. et al. Evaluation of Butyl Rubber as Sorbent Material for the Removal of Oil and Polycyclic Aromatic Hydrocarbons from Seawater. Environ. Sci. Technol. 43, 3846-3852 (2009).

24. Yuan, J. et al. Superwetting nanowire membranes for selective absorption. Nat Nanotechnol. 3, 332-336 (2008).

25. Liang, H.-W. et al. Macroscopic-Scale Template Synthesis of Robust Carbonaceous Nanofiber Hydrogels and Aerogels and Their Applications. Angew. Chem. Int. Ed. 51, 5101-5105 (2012).

26. Choi, S. J. et al. A polydimethylsiloxane (PDMS) sponge for the selective absorption of oil from water. ACS Appl. Mater. Interfaces 3, 4552-4556 (2011).

27. Nardecchia, S., Carriazo, D., Ferrer, M. L., Gutierrez, M. C. \& del Monte, F. Three dimensional macroporous architectures and aerogels built of carbon nanotubes and/or graphene: synthesis and applications. Chem. Soc. Rev. 42, 794-830 (2013).
28. Biener, J. et al. Advanced carbon aerogels for energy applications. Energy Environ Sci. 4, 656 (2011).

29. Li, C. \& Shi, G. Three-dimensional graphene architectures. Nanoscale 4, 5549-5563 (2012).

30. Aliev, A. E. et al. Giant-Stroke, Superelastic Carbon Nanotube Aerogel Muscles. Science 323, 1575-1578 (2009).

31. Chen, Z. et al. Three-dimensional flexible and conductive interconnected graphene networks grown by chemical vapour deposition. Nat. Mater. 10, 424-428 (2011).

32. Kim, K. H., Oh, Y. \& Islam, M. F. Graphene coating makes carbon nanotube aerogels superelastic and resistant to fatigue. Nat. Nanotechnol. 7, 562-566 (2012).

33. Zhao, Y. et al. A Versatile, Ultralight, Nitrogen-Doped Graphene Framework. Angew. Chem. Int. Ed. 51, 11371-11375 (2012).

34. Wu, Z. S. et al. 3D nitrogen-doped graphene aerogel-supported $\mathrm{Fe} 3 \mathrm{O} 4$ nanoparticles as efficient electrocatalysts for the oxygen reduction reaction. J. Am. Chem. Soc. 134, 9082-9085 (2012).

35. Gui, X. et al. Carbon nanotube sponges. Adv. Mater. 22, 617-621 (2010).

36. Bi, H. et al. Spongy Graphene as a Highly Efficient and Recyclable Sorbent for Oils and Organic Solvents. Adv. Funct. Mater. 22, 4421-4425 (2012).

37. Zhao, J., Ren, W. \& Cheng, H.-M. Graphene sponge for efficient and repeatable adsorption and desorption of water contaminations. J. Mater. Chem. 22, 20197 (2012).

38. Sun, H., Xu, Z. \& Gao, C. Multifunctional, Ultra-Flyweight, Synergistically Assembled Carbon Aerogels. Adv. Mater. 25, 2554-2560 (2013).

39. Wu, Z.-Y., Li, C., Liang, H.-W., Chen, J.-F. \& Yu, S.-H. Ultralight, Flexible, and Fire-Resistant Carbon Nanofiber Aerogels from Bacterial Cellulose. Angew. Chem. Int. Ed. 52, 2925-2929 (2013).

40. Liang, H.-W., Liu, J.-W., Qian, H.-S. \& Yu, S.-H. Multiplex Templating Process in One-Dimensional Nanoscale: Controllable Synthesis, Macroscopic Assemblies, and Applications. Acc. Chem. Res. 46, 1450-1461 (2013).

41. Yu, M., Funke, H. H., Falconer, J. L. \& Noble, R. D. High Density, VerticallyAligned Carbon Nanotube Membranes. Nano Lett. 9, 225-229 (2008).

42. Fu, R. et al. The Fabrication and Characterization of Carbon Aerogels by Gelation and Supercritical Drying in Isopropanol. Adv. Funct. Mater. 13, 558-562 (2003).

43. Wu, D., Fu, R., Zhang, S., Dresselhaus, M. S. \& Dresselhaus, G. Preparation of lowdensity carbon aerogels by ambient pressure drying. Carbon 42, 2033-2039 (2004).

44. Vamvakaki, V., Tsagaraki, K. \& Chaniotakis, N. Carbon Nanofiber-Based Glucose Biosensor. Anal. Chem. 78, 5538-5542 (2006).

45. Wu, Z. S. et al. Three-dimensional nitrogen and boron co-doped graphene for high-performance all-solid-state supercapacitors. Adv. Mater. 24, 5130-5135 (2012).

46. Lillo-Ródenas, M. A., Cazorla-Amorós, D. \& Linares-Solano, A. Behaviour of activated carbons with different pore size distributions and surface oxygen groups for benzene and toluene adsorption at low concentrations. Carbon 43, 1758-1767 (2005).

47. Cong, H.-P., Ren, X.-C., Wang, P. \& Yu, S.-H. Macroscopic Multifunctional Graphene-Based Hydrogels and Aerogels by a Metal Ion Induced Self-Assembly Process. ACS Nano 6, 2693-2703 (2012).

48. Qian, H.-S., Yu, S.-H., Gong, J.-Y., Luo, L.-B. \& Fei, L.-f. High-Quality Luminescent Tellurium Nanowires of Several Nanometers in Diameter and High Aspect Ratio Synthesized by a Poly (Vinyl Pyrrolidone)-Assisted Hydrothermal Process. Langmuir 22, 3830-3835 (2006).

\section{Acknowledgments}

We acknowledge the funding support from the the Ministry of Science and Technology of China (Grants 2012BAD32B05-4, 2010CB934700, 2013CB933900, 2014CB931800), the National Natural Science Foundation of China (Grants 91022032, 91227103, 21061160492 J1030412), and the Chinese Academy of Sciences (Grant KJZD-EW-M01-1). We thank Professor Duttwyler Simon for editing the English language of the manuscript.

\section{Author contributions}

S.H.Y. supervised the project and designed the experiments. Z.Y.W. and C. L. performed the experiments, collected and analyzed the data. S.H.Y., Z.Y.W., and H.W.L co-wrote the paper. All of the authors commented the manuscript.

\section{Additional information}

Supplementary information accompanies this paper at http://www.nature.com/ scientificreports

Competing financial interests: The authors declare no competing financial interests How to cite this article: $\mathrm{Wu}, \mathrm{Z}$.-Y. et al. Carbon nanofiber aerogels for emergent cleanup of oil spillage and chemical leakage under harsh conditions. Sci. Rep. 4, 4079; DOI:10.1038/ srep04079 (2014)

This work is licensed under a Creative Commons AttributionNonCommercial-ShareAlike 3.0 Unported license. To view a copy of this license, visit http://creativecommons.org/licenses/by-nc-sa/3.0 